\title{
Development Opportunity of Cultural Industry in Fujian Province under the Strategy of Free Trade Zone
}

\author{
Dong CHEN \\ School of Cultural Creativity and Communication, Minjiang University \\ Fujian, Fuzhou, 3500000
}

\begin{abstract}
The establishment of China (Fujian) Pilot Free Trade Zone has not only brought great historical opportunities for the development of cultural industry in Fujian Province, but also brought severe challenges to the cultural industry. At present, the cultural industry in Fujian Province should seize the opportunity of institutional innovation brought by Pilot Free Trade Zone, enhance the competitiveness of local cultural industry, and ease the pressure of transformation brought by reform.
\end{abstract}

Keywords-Free Trade Zone; Fujian Province; Cultural industry; Development opportunities

\section{INTRODUCTION}

In the past decade, the cultural industry of Fujian Province has shown a rapid development trend, starting from scratch in scale, from low to high in quality, and has become increasingly prominent in the economic and social development of Fujian Province. With the implementation of the strategy of China (Fujian) Pilot Free Trade Zone, the industrial environment of cultural industry development in Fujian Province will be further optimized. As an important measure of the open economic system, the free trade zone strategy includes not only the liberalization of trade in goods, but also involves the fields of trade in services, investment, intellectual property protection and the standardization of related industries, etc.. Therefore, the establishment of China (Fujian) Pilot Free Trade Zone has undoubtedly brought great historical opportunities for the development of cultural industry of Fujian Province, and its implemented negative list management mode has facilitated the participation of cultural industry in international trade[1] ; The innovation of intellectual property protection system will help to guide the healthy and orderly development of cultural industry. Its opening up in the field of financial services provides a more effective financing platform for the development of cultural industries[2]; The principle of "opening up the front line and keeping the second line under control" has opened a "green light" for the participation of cultural and trade enterprises in exhibition, which has also led to the rapid development of cultural tourism industry.

At present, with the acceleration of the construction of Free Trade Zone of Fujian, the characteristics of Fujian to Taiwan are highlighted. Further deepening cultural industry cooperation between Fujian and Taiwan is the common demand of the two places. From the relevant existing literatures, the studies on cultural industries of Fujian and Taiwan mainly focus on three aspects: The first is to analyze the complementarity of cultural industries of Fujian and Taiwan. Guiru LIU and Xiaoxin LIU (2006) discussed the complementarity of cultural industries of Fujian and Taiwan in aspect of product structure, industrial foundation, human resources, operation and marketing experience, and the industrialization mechanism of local culture, etc.. Jian WANG (2012) believed that the cultural industries of Fujian and Taiwan have obvious complementary advantages in capital elements, human resources and market capacity, etc.. The second one is to sum up the experience of Taiwan's cultural industry development and enlightenment to Fujian. Ning GUAN (2011) selected a typical case of the development of Taiwan's cultural creative industry to extract the unique experience of the development of Taiwan's cultural creative industry. Liying ZHOU and Zhaobin LI (2015) summarized the experience in the development of Taiwan's cultural creative industry in the management system, legal protection, business model, market operation model and other aspects, to provide reference for Fujian. The third one is to discuss the countermeasures and thinking of cultural industry cooperation between Fujian and Taiwan. In view of the status quo and problems of Fujian-Taiwan cultural industry cooperation platform, Shulan LIU (2013) put forward suggestions on strengthening the construction of Fujian-Taiwan cultural industry cooperation platform in the organization, talent, information and brand and other aspects. Zhongyan LIN, Dachuan ZHENG and Lei HUANG (2014) discussed the linkage mechanism of cultural creative industries of Fujian and Taiwan, and put forward specific ideas for cooperation between Fujian and Taiwan in the cultural creative industry. From the view of current research situation, there are few documents on the comparative study of the competitiveness of Fujian and Taiwan's cultural industries. Cailing XU and Chunli WANG (2014) made a comparative analysis of the competitiveness of Fujian and Taiwan's cultural industries from four aspects: the scale of the cultural industry, the contribution of the cultural industry, the foundation of the cultural industry and the development environment of the cultural industry, but the selected indicators were relatively unitary and statistical calibers are not exactly the same and the comparability needs to be further improved. Suyan KONG (2013) was based on the 
"three degrees and three forces" level to make a comparative analysis of the competitiveness of Fujian and Taiwan's cultural industries, but aimed at the development situation of cultural industries in the major cities of Fujian and Taiwan. In order to promote the development level of the cultural industry of Fujian Province, it is necessary to have a thorough understanding of the development situation of Fujian and Taiwan's cultural industries and learn from Taiwan's cultural industry competitive advantages.

\section{THE PROBLEMS FACED BY THE DEVELOPMENT OF}

\section{FUJIAN'S CULTURAL INDUSTRY AGAINST THE BACKDROP OF} THE FREE TRADE ZONE AND THEIR COUNTERMEASURES.

The construction of China (Fujian) Pilot Free Trade Zone will also bring severe challenges to the cultural industry. For a long time, China has more or less protective policies in the development of cultural industry. With the implementation of the opening-up strategy promoted in the free trade zone, Fujian Province is attracting many foreign cultural enterprises and products, while the local cultural industry is also facing increasing impact and pressure. At present, the rapid development of China's economy provides a good environment for the development of the cultural industry, and the market demand of the domestic cultural industry has reached an unprecedented level. Compared with the vigorous development of the domestic cultural market, the foreign cultural market has entered a saturated stage, which attracts many foreign cultural capital or enterprises to enter the market of our country urgently. Compared with many foreign cultural enterprises with mature business operation mode, the overall development of cultural enterprises in Fujian Province is unbalanced, the integrity of the industry is insufficient, and the laws and regulations on cultural empowerment are not sound enough. Therefore, with the strong presence of foreign cultural enterprises in China (Fujian) Pilot Free Trade Zone, by virtue of advantages of their own technologies and capital, it must have an impact on the independent innovation of Fujian's cultural industry. Therefore, the cultural industry in Fujian Province should seize the opportunity of institutional innovation brought by the Free Trade Zone, enhance the competitiveness of local cultural industry, and ease the pressure of transformation brought by the reform.

First of all, a multi-level policy support system we should be built to enhance the competitiveness of cultural industry of Fujian Province. From the view of current development experience of countries or regions with the relatively developed cultural industries such as Singapore, Dubai and New York, most of them rely on the policy advantages of their local free trade zones to develop cultural industries. The government has given support of the standards similar to the Green Box Policy of WTO, which is a multi-level and multi-dimensional support. For example, the Singapore Government supports the cultural industry through specific policies such as direct government input, tax incentives and industrial planning, while New York, Hong Kong and other places provide a good industrial development environment for the cultural industry by providing more strategic support such as public services. Therefore, in order to enhance the competitiveness of Fujian's cultural industry, the government should build a multi-level policy support system in combination with the policy convenience of the Pilot Free Trade Zone, give strong support to the cultural industry from the macro-strategic level or the specific policy level, and provide a fair and transparent industry competition environment and development environment. On the one hand, it is necessary to formulate a reasonable development plan for the cultural industry of Fujian Province combined with the regional characteristics and comparative advantages of Fujian Province, and give full guidance to the development of the cultural industry. On the other hand, it is necessary to establish a unified cultural industry management institution, draw lessons from the operation mode of Singapore's Media Authority, optimize the government-led cultural industry development management system by means of market-oriented operation, thus speeding up the cultivation and development of core elements such as cultural industry capital.

Secondly, it is necessary to pay attention to the development of characteristic cultural industries and make clear the demand of the industrial market. As an economic industry, cultural industry must have its output problems, and the output must have a market. In order to develop cultural industry in a country or region, the first step is to develop its unique cultural resources, satisfy its industrial market demand and form a stable brand effect before breaking through the problem. For example, Singapore is mainly relying on its multi-ethnic regional characteristics to create a diversified cultural products and services, and Hong Kong's cultural products market is to give full play to the regional advantages of the free port, integrating local and foreign residents' consumption demands, to meet the needs of local residents while exporting products. New York is to highlight the characteristics of its cultural industry development agglomeration, so as to achieve its advantage of scale economies. Relatively speaking, Fujian Province itself has rich cultural resources and cultural heritage, which is an important basic condition for the development of cultural industry of Fujian. Although the implementation of the free trade zone strategy will introduce many foreign cultural enterprises, after all, it has a cognitive process of local culture, often lack of indepth excavation of cultural resources of Fujian. Therefore, it is necessary to pay attention to the development and utilization of local cultural resources, effectively integrate cultural resources, enhance their transformation abilities, develop special cultural industry projects, especially pay attention to the analysis of cultural market demand and marketing, constantly develop derivative products, and increase the added value of cultural products and services[3].

Thirdly, it is necessary to improve the advance talent cultivation and introduction mechanism, train and expand the team of cultural industry in Fujian Province. Competition of talents is the essence of the competition of cultural industries in various countries at present. Cultural talents are not only the intellectual capital on which the development of cultural industry depends, but also promote the upgrading of cultural creative products and industrial innovation. Therefore, countries (or regions) attach great importance to the cultivation of cultural creative talents. For example, the Singapore government has established a cultural creative talent cultivation 
system from primary school, and New York, the United States has a renowned academy of culture and arts at home and abroad, and has formed a cultural industry-related professional talent cultivation system and so on. Through the construction of the cultural creative talent cultivation system, the Korean government has formed a relatively mature personnel training mechanism which can take into account the cultural art and cultural creative industries. It has not only the compound talents who know how to operate, manage and handle the relationship between management and culture well, but also the new cultural industry professional talents who can realize the combination of the latest technology and cultural industries [4]. Fujian Province should take advantage of the opportunity of introducing many cultural creative industry talents in the pilot free trade zone, and attach importance to the combination of internal training and external attraction, and the combination of training the new and promoting the old. Of course, it is necessary to combine the actual situation of cultural industry development in all regions of Fujian Province. The cultural industry in Fuzhou and Xiamen is relatively developed while other regions are still in the initial stage, so targeted training should be carried out. For regions with relatively backward cultural industry base, it is important to accumulate the scale of practitioners to expand the industrial influence. For the regions with relatively developed cultural industry foundation, the construction of compound talents should be emphasized in order to further enhance the development level of cultural industry. It can be considered to use the strength of colleges and universities to cultivate high-level talents of cultural creative industry, or the government can lead or entrust colleges and universities to set up special research institutions of cultural creative industries to cultivate high-level talents of industry. In addition, relying on the policy opportunities of the Pilot Free Trade Zone, green channels can be opened up, such as the provision of venture capital, equity allocation, children's education services and other attractive preferential policies, widely absorbing high-end cultural talents, and increasing the reserve of high-end cultural talents.

Finally, it is necessary to further improve the intellectual property protection system and broaden the new format of the cultural industry. Different from other real economy, the value of cultural industry comes mainly from the creations of artists, and then a brand effect is formed through marketing operation, which is the process of the development of art works into cultural creative industry, and then new forms of artistic expression are continuously extended through re-creation and re-development [5]. Thus, the value chain and industrial chain of cultural creative industry are formed. In the process of generating the value chain, the protection of the originality and its intellectual property rights is to ensure that the benefits generated in this economic activity can be maximized in development and utilization. In the framework of free trade zone policy, cultural industry will be more integrated with financial securities, science and technology networks, cultural and educational industries, and more new businesses and formats will be more easily derived, and of course, more copyright issues will follow. Therefore, the construction of China (Fujian) Pilot Free Trade Zone accelerates the integration of Fujian Province with the world's advanced copyright protection system, which will force Fujian to build a more perfect intellectual property protection system, speed up the construction of the intellectual property protection system meeting the world standard and its related legal basis, so as to ensure the cultural industry gets rid of the stale and brings forth the fresh continuously.

\section{CONCLUSIONS}

This paper makes a systematic and comprehensive comparative analysis on the competitiveness of Fujian's cultural industry in policy support system, characteristic cultural industry development, talent cultivation and introduction mechanism, and intellectual property protection system and other aspects, and puts forward specific countermeasures to enhance the competitiveness of cultural industry.

\section{REFERENCES}

[1] Feier JI Study on Driving Force of the Spread of Urban Concept to the Development of Creative Industry in Shanghai (D). Shanghai Normal University, 2016

[2] Jipeng TIAN; Shaopai LIU; Meng CAI; Kunyi YAO. Free Trade Zone and Cultural Industry Development: Shanghai Issue and International Experience (J). Journal of Shanghai University of International Business and Economics, 2015, (2).

[3] Yingzi PANG. The Experience and Enlightenment of Cultural Industry Development in Singapore [J]. Southeast Asia \& South Asian Studies, 2013 (4).

[4] Zhong FANG. Comparative Study on Economic Effects of Cultural Creative Industries between China and South Korea [D]. Fujian Normal University, 2010

[5] Hui WANG Comparative Study on the Cultural Creative Industry Cluster Areas between Beijing and New York [J]. Social Science of Beijing, 2010 (6). 